\title{
STORM-based Quantitative Assessment of Sodium Channel Localization Relative to Junctional Proteins Within the Cardiac Intercalated Disk
}

\author{
Rengasayee Veeraraghavan ${ }^{1}$, Robert G. Gourdie ${ }^{1,2}$
}

1. Virginia Tech Carilion Research Institute, and Center for Heart and Regenerative Medicine, Virginia Polytechnic University, Roanoke, VA

2. School of Biomedical Engineering and Sciences, Virginia Polytechnic University, Blacksburg, VA

Computer models suggest that ephaptic coupling in the heart is feasible given close apposition $(<30 \mathrm{~nm})$ between sodium channel $\left(\mathrm{Na}_{\mathrm{v}} 1.5\right)$-rich membranes of adjacent myocytes.(1-3) Such close apposition of membranes only occurs in some parts of the intercalated disc (ID). We previously demonstrated $5-10 \mathrm{~nm}$ intermembrane distance within the perinexus, a gap junction (GJ) -adjacent ID nanodomain.(4) Further, gSTED super-resolution microscopy suggest enrichment of $\mathrm{Na}_{\mathrm{v}} 1.5$ within the perinexus. Moreover, experiments disrupting the close apposition of membranes within the perinexus slowed conduction and precipitated arrhythmias. Therefore, we sought to quantify the localization of $\mathrm{Na}_{\mathrm{v}} 1.5$ and its auxiliary subunit $\beta 1$ (SCN1b) relative to connexin43 (Cx43) and N-Cadherin (N-Cad), which respectively served as markers of ID interplicate and plicate regions.

Confocal micrographs of guinea pig ventricular myocardium revealed enrichment of $\mathrm{Na}_{\mathrm{v}} 1.5$ and $\beta 1$ at the ID. Next, we analyzed STORM images of guinea pig ventricular sections immunolabeled for $\mathrm{Na}_{\mathrm{v}} 1.5$ / $\beta 1$ along with $\mathrm{Cx} 43$ and $\mathrm{N}$-cadherin (N-Cad) using custom algorithms. Briefly, the STORM data, comprised of the precise 3D locations of individual fluorophore molecules, was subjected to 3D particle density-based cluster detection. Convex hulls were fit to each cluster and the following parameters evaluated for each cluster of a given protein: 1) degree of overlap with a cluster of the co-labeled protein, and, 2) surface-to-surface distance to the nearest cluster of the co-labeled protein. Overall, less than a quarter of the $\mathrm{Cx} 43$ and $\mathrm{Na}_{\mathrm{v}} 1.5$ clusters overlapped each other. Where overlap occurred, it accounted for less than a quarter of either cluster's volume, suggesting tangential contact (figure 1). However, over half of the $\mathrm{Cx} 43$ clusters identified had $\mathrm{Na}_{\mathrm{v}} 1.5$ located less than $200 \mathrm{~nm}$ away, within the previously reported extent of the perinexus. Interestingly, a second population of $\mathrm{Na}_{\mathrm{v}} 1.5 \mathrm{was}$ identified in regions of high $\mathrm{N}$-Cadherin density where intermembrane spacing exceeds $50 \mathrm{~nm}$.(5) In short, the data suggests two ID-localized populations of $\mathrm{Na}_{\mathrm{v}} 1.5$, one adjacent $\mathrm{Cx} 43$ aggregates, in regions corresponding to the perinexus, and the other co-distributing with $\mathrm{N}$-Cadherin. In contrast, $\beta 1$ was preferentially enriched adjacent $\mathrm{Cx} 43$ with less than $10 \%$ co-distributing with $\mathrm{N}$-Cadherin.

Taken together these data suggest that there may exist two pools of $\mathrm{Na}_{\mathrm{v}} 1.5$ within the ID: One codistributed with $\beta 1$ adjacent $\mathrm{Cx} 43$, where intermembrane distances can be $<=10 \mathrm{~nm}$. The second was not co-distributed with $\beta 1$ and was located in N-Cadherin-rich regions where membrane spacing exceeds $50 \mathrm{~nm}$. Thus, the former $\mathrm{Na}_{\mathrm{v}} 1.5$ pool may be preferentially able to support ephaptic coupling. This hypothesis is further strengthened by previous reports that $\beta 1$ can cluster $\mathrm{Na}_{\mathrm{v}} 1.5$ and also act as a cell adhesion molecule.(6) Therefore, these data suggest a role for $\beta 1$-mediated adhesion in modulating ephaptic coupling.

\section{References:}

[1] Kucera JP, Rohr S, \& Rudy Y, Circulation research 91(12) (2002), p. 1176. 
[2] Lin J \& Keener JP, IEEE transactions on bio-medical engineering 60(2) (2013), p. 576.

[3] Mori Y, Fishman GI, \& Peskin CS, Proceedings of the National Academy of Sciences of the United States of America 105(17) (2008), p. 6463.

[4] Veeraraghavan R, et al. Pflugers Arch. (2015)

[5] Leo-Macias A, Liang FX, \& Delmar M, Cardiovascular research 107(4) (2015), p. 442.

[6] Isom LL, Neuroscientist 7(1) (2001), p. 42.

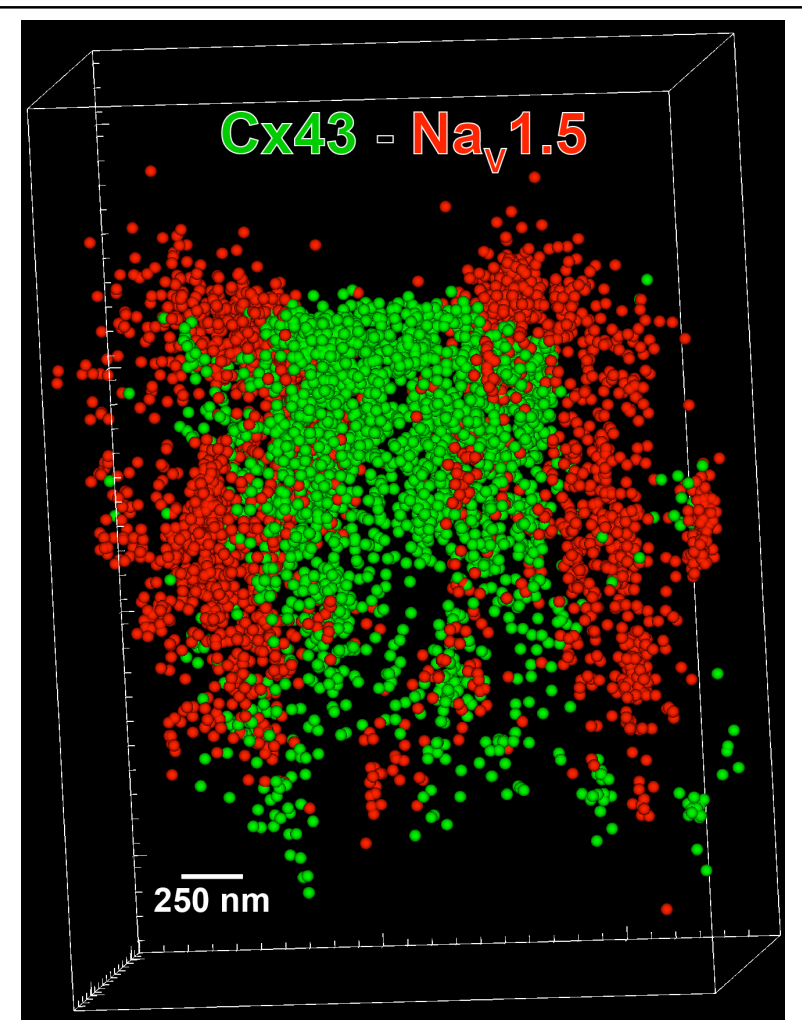

Figure 1. A 3D rendered view of representative STORM data showing a cluster of fluorophores corresponding to $\mathrm{Cx} 43$ (green) flanked by clusters of $\mathrm{Na}_{\mathrm{v}} 1.5$ (red) on either side. Each sphere represents an individual fluorophore molecule localized. 